\title{
Investigation of Telomerase/Telomeres system in Bone Marrow Mesenchymal Stem Cells derived from IPF and RA-UIP
}

\author{
Katerina M Antoniou ${ }^{1,2^{*}+}$, George A Margaritopoulos ${ }^{1,2+}$, Athanasia Proklou ${ }^{1,2}$, Konstantinos Karagiannis ${ }^{2}$, \\ Ismini Lasithiotaki ${ }^{1,2}$, Giannoula Soufla ${ }^{3}$, Maria Christina Kastrinaki ${ }^{4}$, Demetrios A Spandidos ${ }^{3}$, \\ Helen A Papadaki ${ }^{4}$ and Nikos M Siafakas ${ }^{1}$
}

\begin{abstract}
Objective: Idiopathic Pulmonary Fibrosis and Rheumatoid Arthritis associated usual interstitial pneumonia seem to have the same poor outcome as there is not an effective treatment. The aim of the study is to explore the reparative ability of bone marrow mesenchymal stem cells by evaluating the system telomerase/telomeres and propose a novel therapeutic approach.
\end{abstract}

Methods: BM-MSCs were studied in 6 IPF patients, 7 patients with RA-UIP and 6 healthy controls. We evaluated the telomere length as well as the mRNA expression of both components of telomerase (human telomerase reverse transcriptase, h-TERT and RNA template complementary to the telomeric loss DNA, h-TERC).

Results: We found that BM-MSCs from IPF, RA-UIP cases do not present smaller telomere length than the controls $(p=0.170)$. There was no significant difference regarding the expression of both $h$-TERT and h-TERC genes between patients and healthy controls ( $p=0.107$ and $p=0.634$ respectively).

Conclusions: We demonstrated same telomere length and telomerase expression in BM-MSCs of both IPF and RA-UIP which could explain similarities in pathogenesis and prognosis. Maintenance of telomere length in these cells could have future implication in cell replacement treatment with stem cells of these devastating lung disorders.

Keywords: Idiopathic Pulmonary Fibrosis, Bone Marrow Mesenchymal Stem Cells, Rheumatoid Arthritis

\section{Introduction}

Idiopathic pulmonary fibrosis (IPF) is the most devastating form of fibrosing lung diseases with a median survival of 3 years and a prognosis which is worst than that of many cancers $[1,2]$. The underlying pathologic pattern is that of usual interstitial pneumonia (UIP). Although recent studies have suggested that IPF is the result of repeated injuries in different sites of the lung epithelium followed by aberrant wound healing with inadequate

\footnotetext{
* Correspondence: katerinaantoniou@yahoo.gr

${ }^{\dagger}$ Equal contributors

'Department of Thoracic Medicine, Interstitial Lung Disease Unit, University

Hospital of Heraklion, Crete, Greece

${ }^{2}$ Laboratory of Cellular and Molecular Pulmonology, Medical School,

University of Crete, Crete, Greece

Full list of author information is available at the end of the article
}

repair of the epithelial damage, pathogenesis of IPF still remains poorly understood. Consequently and despite recent advances [3-5], there is no effective treatment currently available which can lengthen patient's survival other than lung transplantation. Thus, the need for more effective treatment becomes imperative.

Mesenchymal stem-cells (MSCs) are one of the most intriguing novel therapeutic approaches in the field of chronic diseases [6-12] because of the ability to repair injured tissues. They possess high proliferative capacity and ability to differentiate in adipocytes, condrocytes, osteocytes, endothelial, epithelial and neuronal cells depending on the culture conditions [13]. Moreover, there are data suggesting that bone marrow (BM)-MSCs have the ability to differentiate and function as airway and parenchymal lung cells [14]. It has been shown in animal model of

\section{() Biomed Central}


bleomycin (BLM)-induced fibrosis that (BM)-MSCs express several chemokine receptors such as CXCR4 which ligand, CXCL12, is induced in murine lungs [15-17] suggesting that bone marrow stem cells could be recruited and mobilized to the injured lung through a CXCR4 dependent mechanism. Recently we have shown that CXCR4 is overexpressed in BM-MSCs of patients with IPF [18] suggesting that the abovementioned scenario could also be applied to humans.

Telomeres are repeated DNA sequences acting as protective caps for chromosomes. Telomere shortening is one of the molecular mechanisms underlying ageing and critically short telomeres trigger chromosome senescence and lead to cell death [19]. Telomerase is a specialized polymerase that adds telomere repeats to chromosomes compensating the telomere shortening and consists of two components: a catalytic component, telomerase reverse transcriptase (h-TERT) and an RNA component (h-TERC) [20].

The aim of our research was to investigate the reparative ability of BM-MSCs in patients with IPF by evaluating telomere expression and telomere length and propose a novel therapeutic approach for this dismal disease. In our research we have also included patients with rheumatoid arthritis (RA) as in this disease, when there is interstitial lung involvement and unlike the rest of collagen tissue disorders, the most predominant pathologic pattern is UIP and in this case prognosis is similar to IPF [21]. We aimed to prove that telomere length and telomerase expression are not different in patients group compared to healthy controls proposing the possibility of cell replacement treatment as a novel therapeutic approach.

\section{Patients}

We have studied prospectively 6 patients with IPF, 7 patients with RA-UIP whose characteristics are shown in Table 1. Patients were recruited from the Interstitial Lung Disease Unit (ILDU) at the Department of Thoracic Medicine of Heraklion. The control group included 6 subjects, age-matched with the patients who underwent posterior iliac crest aspirate because of suspected hematologic malignancies. We have included in our research those with negative biopsy results and thus considered as healthy subjects. These patients have been studied retrospectively and we did not have details other than age and gender in order to be matched with the patients.

The diagnosis of IPF was made in 3 cases by surgical biopsy and the histologic diagnosis of Usual Interstitial Pneumonia (UIP) was obtained. In the remaining 3 cases the diagnosis was made according to the recently published ATS/ERS guidelines [1].

The diagnosis of RA-UIP was made in 2 cases by surgical biopsy and the histologic diagnosis of UIP was obtained. In the remaining 5 cases, patients had a "definite
Table 1 Clinical characteristics of the patients studied

\begin{tabular}{llllll}
\hline UPN & Age/sex & Disease & $\begin{array}{l}\text { Duration of } \\
\text { lung disease } \\
\text { (months) }\end{array}$ & $\begin{array}{l}\text { Medication at } \\
\text { presentation }\end{array}$ & FVC/DLCO \\
\hline 1 & $77 / M$ & RA-UIP & 0 & No therapy & $75.3 / 47.2$ \\
\hline 2 & $71 / F$ & RA-UIP & 12 & PDN/AZA/NAC & $68.7 / 22.1$ \\
\hline 3 & $75 / F$ & RA-UIP & 0 & No therapy & $89.7 / 34.8$ \\
\hline 4 & $72 / M$ & RA-UIP & 0 & MTX-LEFLUNEMIDE* & $119.3 / 68.4$ \\
\hline 5 & $76 / F$ & RA-UIP & 6 & PDN/AZA/NAC & $82.8 / 60.1$ \\
\hline 6 & $50 / F$ & RA-UIP & 12 & PDN/AZA/NAC & $94.5 / 49.6$ \\
\hline 7 & $81 / F$ & RA-UIP & 0 & No therapy & $76.5 / 32$ \\
\hline 8 & $74 / M$ & IPF & 0 & No therapy & $70 / 70$ \\
\hline 9 & $78 / M$ & IPF & 0 & No therapy & $41.6 / 25$ \\
\hline 10 & $82 / M$ & IPF & 0 & No therapy & $75.6 / 38.5$ \\
\hline 11 & $85 / M$ & IPF & 0 & No therapy & $88 / 31$ \\
\hline 12 & $70 / M$ & IPF & 0 & No therapy & $83 / 58$ \\
\hline 13 & $72 / M$ & IPF & 0 & No therapy & $75 / 45$
\end{tabular}

Abbreviations: PDN: prednisolone, MTX: methotrexate, AZA: azathioprine, NAC: $\mathrm{N}$-acetyl-cysteine, UPN: unique patient number.

* The patient was on treatment for Rheumatoid Arthritis.

RA-UIP" pattern based on HRCT criteria, with basilar predominant reticulation, traction bronchiectasis and honeycombing, with limited ground-glass opacities [22].

Diagnosis of RA was based on clinical criteria in accordance with the international societies guidelines [23].

Ethical Committee of the University of Crete has approved the study and all participants (patients and control subjects) were informed on the scope of the study and gave their written informed consent $[18,24]$.

\section{Methods}

\section{BM-MSCs in vitro expansion and differentiaition}

BM mononuclear cells (BMMCs) obtained from posterior iliac crest aspirates were cultured in Dulbecco's Modified Eagle Medium-Low Glucose (DMEM-LG; Gibco/ Invitrogen, Paisley, Scotland) $/ 10 \%$ fetal calf serum (FCS; Hyclone, Logan-Utah,USA)/100 IU/ml PenicilineStreptomycin (MSC medium) and MSCs were grown and flow cytometric analysis of MSCs in each passage was performed as previously described [25,26]. Upon reaching confluency at passage 2 (P2) trypsinized MSCs were centrifuged and after performing a cell count in a Neubauer haemocytometer at least 1.000 .000 cells were used for further processing.

MSCs from P2 were induced for differentiation. Adipogenic differentiation was induced following 21-day culture of cells in MSC medium supplemented with $10 \%$ FCS/0.5 mM 1-methyl-3-butylisoxanthine/1 $\mu \mathrm{M}$ dexamethasone (Dex) $/ 0.2 \mu \mathrm{M}$ indomethacin $/ 10 \mu \mathrm{g} / \mathrm{ml}$ insulin and adipogenesis was assessed by Oil Red $\mathrm{O}$ staining. Osteogenic differentiation was induced following 21-day culture of cells in MSC medium supplemented with $0.1 \mu \mathrm{M}$ Dex/0.15 mM ascorbate-2-phosphate/3 $\mathrm{mM}$ 
$\mathrm{NaH}_{2} \mathrm{PO}_{4}$ and osteogenesis was assessed by alkaline phosphatase (ALP)/von Kossa staining. For chondrogenic induction, MSCs were pelleted in $15 \mathrm{ml}$ tubes and cultured for 21 days in DMEM-High Glucose (Gibco), supplemented with $6.25 \mu \mathrm{g} / \mathrm{ml}$ insulin $/ 6.25 \mu \mathrm{g} / \mathrm{ml}$ transferring/1.33 $\mu \mathrm{g} / \mathrm{ml}$ linoleic acid/1.25 $\mathrm{mg} / \mathrm{ml}$ bovine serum albumin/1 $\mathrm{mM}$ sodium pyruvate/0.17 $\mathrm{mM}$ ascorbate-2-phosphate/0.1 $\mu \mathrm{M}$ Dex/0.35 mM L-proline/ $6.25 \mathrm{ng} / \mathrm{ml}$ selenous acid/0.01 $\mu \mathrm{g} / \mathrm{ml}$ transforming growth factor- $\beta 1$ (R\&D Systems) and chondrogenesis was assessed by Alcian blue stain. All reagents were purchased from Sigma unless otherwise indicated.

\section{BM-MSCs immunophenotypic characteristics}

Trypsinised MSCs from P2 were immunophenotypically characterised by flow-cytometry, using anti-CD29 (4B4; Cyto-Stat, Beckman-Coulter, Fullerton, California, USA), anti-CD44 (J173; Immunotech/Coulter, Marseille, France), anti-CD73 (AD2; Pharmingen, San Diego, California, USA), anti-CD90 (F15.42; Immunotech/Coulter), antiCD105 (SN6; Caltag, Burlingame, California, USA), antiCD146 (P1H12; Pharmingen), anti-CD45 (IMMU19.2; Immunotech/Coulter), anti-CD14 (RMO52; Immunotech/ Coulter) and anti-CD34 (QBend10; Beckman-Coulter) monoclonal antibodies.

\section{Real-time reverse transcriptase-polymerase chain} reaction assay

MSCs at P2 were homogenized in the TRIzol ${ }^{\circledR}$ reagent (Invitrogen, Carlsband, CA), total RNA was extracted and cDNA synthesized by reverse transcription (RT) with the Thermoscript ${ }^{\mathrm{TM}}$ RT kit (Invitrogen). Genes mRNA expression was measured using a real-time RTPCR assay with SYBR-Green I. $\beta$-actin was used as the internal control, in order to normalize h-TERT and h-TERC expression levels. The mRNA-specific primers used are listed in Table 2.

Table 2 Primer sequences used for quantitative Real-time RT-PCR

\begin{tabular}{lll}
\hline Gene & Primer pair sequence (5'-3') & $\begin{array}{l}\text { Annealing } \\
\text { temperature }\end{array}$ \\
\hline hTERT & FOR: TGACACCTCACCTCACCCAC & $51^{\circ} \mathrm{C}$ \\
& REV: CACTGTCTTCCGCAAGTTCAC & \\
\hline hTERC & FOR: GCCTGCCGCCTTCCACCGTTCATT & $59^{\circ} \mathrm{C}$ \\
& REV: GACTCGCTCCGTTCCTCTTCCTG & \\
\hline TELOMERE & FOR: CGGTTGTTTGGTTTGGG & $56^{\circ} \mathrm{C}$ \\
& TTTGGTTTGGTTGGGTT & \\
& REV: GGCTTGCCTTACCCTTACC & \\
\hline ACTIN & CTTACCCTTACCCTACCCT & \\
& FOR: CGGCATCGTCACCAACTG & $58^{\circ} \mathrm{C}$ \\
& REV: GGCACACGCAGCTCATTG & \\
\hline
\end{tabular}

\section{Telomere length measurement}

The relative telomere length was estimated by real-time PCR as described originally by Cawthon [27], with minor modifications. $\beta$-Globin (HBG) was used as control single-copy-gene. Primer sequences are listed in Table 3. Genomic DNA was extracted from P2 MSCs using TRIzol_ reagent (Invitrogen, Carlsband, CA). 35 ng of DNA were used for the reactions in a final volume of $20 \mu \mathrm{l}$. iTaq SYBR Green Supermix with ROX (Biorad, Hercules,CA) was used for the PCR reactions. The concentrations of reagents for telomere PCRs were $1 \mathrm{X}$ iTaq SYBR Green Supermix, 100nM forward, and 900nM reverse primers. For HBG reactions $400 \mathrm{nM}$ were used from each primer. For telomere PCRs, 40 cycles were conducted: $15 \mathrm{~s}$ at $95{ }^{\circ} \mathrm{C}$ and $1 \mathrm{~m}$ at $56^{\circ} \mathrm{C}$. For HBG PCRs, 40 cycles were performed: $15 \mathrm{~s}$ at $95{ }^{\circ} \mathrm{C}$ and $1 \mathrm{~m}$ at $58{ }^{\circ} \mathrm{C}$. PCRs were carried out in Mx3000P Real-Time PCR system (Stratagene, La Jolla, CA, USA). All reactions were performed in duplicates. The relative telomere length was reflected by the $T / S$ ratio, where $T$ is the amount of telomere $\left(\mathrm{T}=2^{\text {-Ct telomere }}\right)$ and $\mathrm{S}$ is the amount of the single-copy-gene $\left(\mathrm{S}=2^{-\mathrm{Ct} H \mathrm{HBG}}\right): \mathrm{T} / \mathrm{S}=2^{\text {-Ct telomere }}$ / $2^{-\mathrm{Ct} \text { HBG }}=2^{-(\mathrm{Ct} \text { telomere-Ct HBG) }}=2^{-\Delta \mathrm{Ct}}$.

\section{Statistical analysis}

Differences in relative telomere length and m-RNA expression of $\mathrm{h}$-TERC and $\mathrm{h}$-TERT genes between patients group and controls have been tested with Kruskal-Wallis test and a value of $\mathrm{p}<0.05$ has been considered significant.

\section{Results}

MSCs immunophenotype and differentiation potential

Immunophenotypic analysis of MSCs from all groups of patients and healthy controls at the end of P2 demonstrated that cultures constituted of a homogenous cell population positive for CD73, CD90, CD146, CD105, CD29, CD44 and negative for CD45 and CD34 surface antigens. P2 MSCs were able to differentiate towards the adipogenic, osteogenic and chondrogenic lineages in healthy individuals, as well as in all groups of patients.

\section{Telomerase expression and telomere length}

We found that the relative telomere length in both patients group (IPF and RA-UIP) did not differ compared to healthy controls $(p=0.17)$. This finding suggests that BM-MSCs obtained from patients group are

Table 3 Primer sequences used for relative telomere length estimation with RT-PCR

\begin{tabular}{|c|c|c|}
\hline & Forward & Reverse \\
\hline Telomere & $\begin{array}{l}\text { 5'CGGTTGTTTGGGTTGGG } \\
\text { TITGGGTTGGGTTGGGTT-3' }\end{array}$ & $\begin{array}{l}\text { 5'GGCTTGCCTTACCCTTACC } \\
\text { CTTACCCTTACCCTTACCCT-3' }\end{array}$ \\
\hline HBG & $\begin{array}{l}\text { 5'GCTTCTGACACAACTGTGT } \\
\text { TCACTAGC-3' }\end{array}$ & $\begin{array}{l}\text { 5'-CACCAACTTCATCCACGT } \\
\text { TCACC- } 3^{\prime}\end{array}$ \\
\hline
\end{tabular}


Table 4 Relative telomere length in the three study groups

\begin{tabular}{lllll}
\hline & RA-UIP & IPF & Controls & p-value \\
\hline Telomere length & 0.663 & 1.118 & 1.876 & 0.170 \\
& $(1.476,11.548)$ & $(0.747,9.867)$ & $(0.038,3.221)$ & \\
\hline
\end{tabular}

Comparison was performed with Kruskall Wallis $\mathrm{H}$ test. Values are presented as median (interquartile ranges).

able to maintain telomere length and therefore could be proposed as possible replacement treatment (Table 4 and Figure 1).

Both h-TERT and h-TERC genes were expressed at the m-RNA level in all patients' group and control subjects. However, we did not observe any statistically significant difference in gene expression of h-TERT and h-TERC between study groups $(\mathrm{p}=0.107$ and $\mathrm{p}=0.634$ respectively) (Table 5).

\section{Discussion}

It is well known that IPF is the result of multiple injuries in different sites of lung epithelium followed by inadequate repair characterised by the migration of resident fibroblasts, BM progenitors of fibroblasts (fibrocytes) and fibroblasts derived from a process called epithelialmesenchymal transition (EMT), formation of fibroblast and myofibroblast foci and exaggerated production of extracellular matrix (ECM). The subgroup of patients with RA associated interstitial lung disease who present with the underlying pathologic pattern of UIP has the same prognosis with IPF [22] suggesting the possibility of shared pathogenetic pathways. For both diseases there is still no effective treatment other than lung transplantation. Cell replacement treatment with MSCs is promising because of the proliferation capacity and ability of these cells to repair injured tissues.

Telomeres shorten successively with each cell division and when they achieve a critical length, activate a p53-

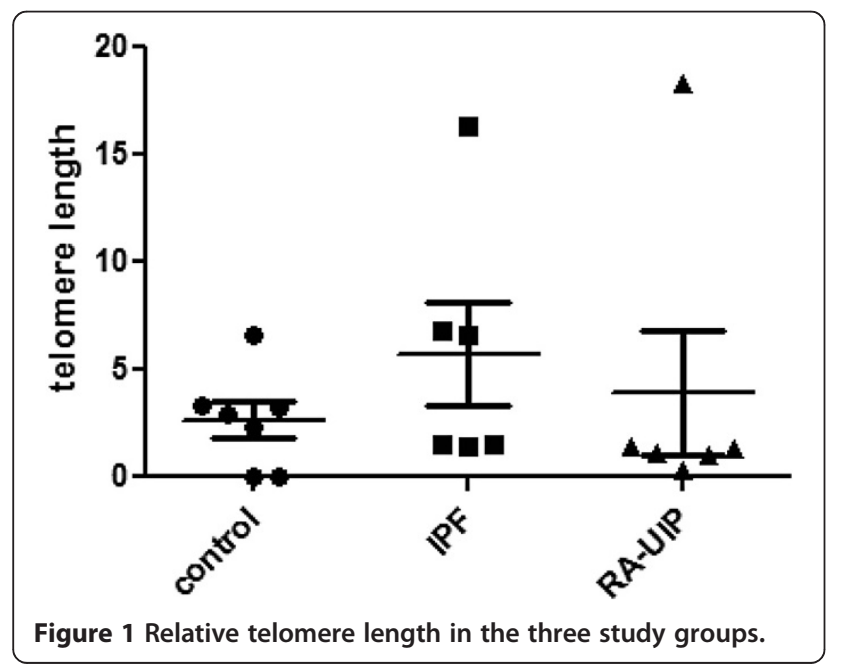

Table 5 mRNA expression of hTERT and hTERC in the three study groups

\begin{tabular}{lllll}
\hline & RA-UIP & IPF & Controls & p-value \\
\hline hTERT & $0.50(0.00,1.30)$ & $1.45(0.78,21.37)$ & $0.50(0.27,0.77)$ & 0.107 \\
\hline hTERC & $0.10(0.00,3.60)$ & $0.05(0.00,6.78)$ & $0.20(0.08,0.20)$ & 0.634 \\
\hline
\end{tabular}

Comparison was performed with Kruskall Wallis $\mathrm{H}$ test. Values are presented as median (interquartile ranges).

dependent mechanism that leads to apoptosis or replicative senescence [28]. Short telomeres are expected to compromise the replicative potential of progenitor cells that remain in tissues after injury. We aimed to show that telomeres from patients with IPF and RA-UIP are able to maintain telomeres length despite the high proliferation capacity and thus maintain the reparative ability. Our most important finding is that BM-MCSs from patients present relative telomere length which did not differ compared to healthy controls and thus could be used for autologous transplant. Moreover, they express, although weakly, both genes of telomerase at the same level with healthy controls suggesting a plausible mechanism for the maintenance of telomere length. The findings of the current study are not similar with previous findings of our group [29]. However, it should be stressed that these were preliminary findings of our work and patients included in that cohort were older, had more severe disease (DLCo $<30 \%$ ), with few of them on ambulatory oxygen, than the patients included in the current cohort. In addition, it was previously observed that $25 \%$ of sporadic cases with IPF had shorter telomeres in peripheral leukocytes without coding mutations in telomerase [30] and we believe that this scenario could also be applied to BM-MSCs explaining the discrepancy of the findings between the two studies.

Recent studies have shown that MSCs may abrogate fibrosis, but unfortunately in most of them, an animal model of BLM-induced fibrosis has been used and as it is known, this model does not represent the progressive and lethal nature of IPF. Nonetheless, MSCs seem to partially abolish lung injury in animal models of fibrosis, emphysema and inflammatory lung injury and participate in organ regeneration [31]. Interestingly, lung engraftment of MSCs administered systematically occurs at low levels in normal mice whereas it is increased in injured murine lung after exposure to BLM. MSCs adopt an epithelial-like phenotype and have a beneficial effect by reducing inflammation, collagen deposition and metalloproteinases activation within lung tissue [32]. Additionally, in another study it was observed that prominin-1/CD133(+) epithelial progenitor cells expanded from adult mouse lung and of bone marrow origin, are able to express both stem and haematopoietic cell markers and differentiate in vitro into type II epithelial cells. When intratracheally administered in mice treated 
with BLM, they engrafted into the lungs, differentiated into type II epithelial cells and suppressed proinflammatory and profibrotic gene expression protecting form the development of pulmonary fibrosis [33]. Alternatively to BM-MSCs, embryonic stem cells (ESCs) which present similar ability to differentiate in any cell of the body have been studied as replacement treatment. Alveolar epithelial type II cells derived from human ESCs were transplanted in the lungs of mouse treated with BLM and differentiated into type I alveolar epithelial cells abrogating the inflammatory and fibrotic response [34].

The system telomerase/telomere has been implicated in the pathogenesis of IPF. It was observed that mutations in both components of telomerase are present in $8-15 \%$ of patients with familial IPF $[35,36]$. On the other hand, mutations in the essential telomerase genes are also present in $1-3 \%$ of sporadic cases [30,37]. Plainly mutations lead to loss of telomerase function and to telomere shortening. Interestingly though, it was observed that in sporadic cases of IPF telomeres are short in lymphocytes, granulocytes and alveolar epithelial cells compared to age-matched controls even in absence of telomerase mutations $[30,37]$.

Considering the fact that BM-MSCs have high mitotic activity and go through a large number of replication, one may expect that they express high levels of telomerase in order to prevent telomere shortening. Surprisingly and in accordance with our findings, it was observed that adult stem cells express low levels of telomerase and telomerase activity is low $[38,39]$. This may be a defensive mechanism against malignant transformation as it was shown that adult stem cells play an important role in cancer development and maintenance [40-43]. Plainly, there may be another mechanism of telomere maintenance other than telomerase. It is suggested that the alternative lengthening of telomeres pathway, a recombination based DNA replication mechanism, may maintain telomere length $[44,45]$. In addition, it was observed that subtelomeric hypomethylation facilitates telomere elongation in mammalian cells suggesting that such epigenetic modification of cromatin may occur also in MSCs [46]. On the other hand, even a low telomerase expression and activity are required for both replication and differentiation as it is shown that MSCs from a telomerase activity knocked-down mouse failed to differentiate into adipocytes or condrocytes and that telomerase overexpressing human MSCs have enhanced in vivo bone formation potential $[47,48]$.

In conclusion, we have shown that BM-MSCs from patients with IPF and RA-UIP maintain the same telomere length with healthy donors suggesting the possible use of these cells in cell replacement treatment for both diseases. The same treatment has been also proposed for other chronic diseases such as amyotrophic lateral sclerosis (AML) [49] as it was found that human BMMSCs from patients present the same telomere length with healthy donors. Plainly, caution is recommended as there are a lot of issues that need to be clarified such as whether the level of lung engraftment is sufficient for regenerative purposes, the likelihood of cell rejection, and the possibility of causing local damage i.e. favouring the development of fibrosis or lung neoplasms [50]. Definitely, further studies are needed before start using stem cells safely for pulmonary diseases.

\section{Competing interests}

The author(s) declare that they have no competing interests.

\section{Author details}

'Department of Thoracic Medicine, Interstitial Lung Disease Unit, University Hospital of Heraklion, Crete, Greece. 'Laboratory of Cellular and Molecular Pulmonology, Medical School, University of Crete, Crete, Greece. ${ }^{3}$ Laboratory of Clinical Virology, Medical School, University of Crete, Heraklion, Crete, Greece. ${ }^{4}$ Hematopoiesis Research Laboratory, Medical School, University of Crete, Crete, Greece.

\section{Authors' contribution}

KMA and GAM designed the study, performed the statistical analysis and wrote the manuscript. AP and KK contributed to patients recruitment and evaluation. IL and GS carried out the RT-PCRs. MCK and HAP obtained the posterior iliac crest aspirates. DAS and NMS coordinated the study and helped to draft the manuscript. All read and approved the final version of the manuscript.

Received: 13 December 2011 Accepted: 2 July 2012

Published: 2 July 2012

\section{References}

1. Raghu G, Collard HR, Egan JJ, Martinez FJ, Behr J, Brown KK, et al: An official ATS/ERS/JRS/ALAT statement: idiopathic pulmonary fibrosis: evidence-based guidelines for diagnosis and management. Am J Respir Crit Care Med 2011, 183:788-824.

2. Vancheri C, Failla M, Crimi N, Raghu G: Idiopathic pulmonary fibrosis: a disease with similarities and links to cancer biology. Eur Respir J 2010, 35:496-504.

3. Demedts M, Behr J, Buhl R, Costabel U, Dekhuijzen R, Jansen HM, et al: High-dose acetylcysteine in idiopathic pulmonary fibrosis. N Engl I Med 2005, 353:2229-2242.

4. Behr J, Demedts M, Buhl R, Costabel U, Dekhuijzen RP, Jansen HM, et al: Lung function in idiopathic pulmonary fibrosis-extended analyses of the IFIGENIA trial. Respir Res 2009, 10:101.

5. Taniguchi H, Ebina M, Kondoh Y, Ogura T, Azuma A, Suga M, Taguchi Y, Takahashi H, Nakata K, Sato A, Takeuchi M, Raghu G, Kudoh S, Nukiwa T: Pirfenidone Clinical Study Group in Japan. Pirfenidone in idiopathic pulmonary fibrosis. Eur Respir J 2010, 35:821-829.

6. Beyth S, Borovsky Z, Mevorach D, Liebergall M, Gazit Z, Aslan H, et al: Human mesenchymal stem cells alter antigen-presenting cell maturation and induce T-cell unresponsiveness. Blood 2005, 105:2214-2219.

7. Gronthos S, Mankani M, Brahim J, Robey PG, Shi S: Postnatal human dental pulp stem cells (DPSCs) in vitro and in vivo. Proc Natl Acad Sci U S A 2000, 97:13625-13630

8. Hall B, Dembinski J, Sasser AK, Studeny M, Andreeff M, Marini F: Mesenchymal stem cells in cancer: tumor-associated fibroblasts and cellbased delivery vehicles. Int J Hematol 2007, 86:8-16.

9. Hare JM, Traverse JH, Henry TD, Dib N, Strumpf RK, Schulman SP, et al: A randomized, double-blind, placebo-controlled, dose-escalation study of intravenous adult human mesenchymal stem cells (prochymal) after acute myocardial infarction. J Am Coll Cardiol 2009, 54:2277-2286.

10. Tzouvelekis A, Antoniadis A, Bouros D: Stem cell therapy in pulmonary fibrosis. Curr Opin Pulm Med 2011, 17:368-373. 
11. Stripp BR, Shapiro SD: Stem cells in lung disease, repair, and the potential for therapeutic interventions: State-of-the-art and future challenges. Am J Respir Cell Mol Biol 2006, 34:517-518.

12. Wolf $D$, Wolf AM: Mesenchymal stem cells as cellular immunosuppressants. Lancet 2008, 371:1553-1554.

13. Prockop DJ: Marrow stromal cells as stem cells for nonhematopoietic tissues. Science 1997, 276:71-74.

14. Loebinger MR, Aguilar S, Janes SM: Therapeutic potential of stem cells in lung disease: progress and pitfalls. Clin Sci (Lond) 2008, 114:99-108.

15. Abe R, Donnelly SC, Peng T, Bucala R, Metz CN: Peripheral blood fibrocytes: differentiation pathway and migration to wound sites. $\mathrm{J}$ Immunol 2001, 166:7556-7562.

16. Hashimoto N, Jin H, Liu T, Chensue SW, Phan SH: Bone marrow derived progenitor cells in pulmonary fibrosis. J Clin Invest 2004, 113:243-252.

17. Phillips RJ, Burdick MD, Hong K, Lutz MA, Murray LA, Xue YY, Belperio JA, Keane MP, Strieter RM: Circulating fibrocytes traffic to the lungs in response to CXCL12 and mediate fibrosis. J Clin Invest 2004, 114:438-446.

18. Antoniou KM, Papadaki HA, Soufla G, Kastrinaki MC, Damianaki A, Koutala H, Spandidos DA, Siafakas NM: Investigation of bone marrow mesenchymal stem cells (BM MSCs) involvement in idiopathic pulmonary fibrosis (IPF). Respir Med 2010, 104:1535-1542.

19. O'Sullivan RJ, Karlseder J: Telomeres: protecting chromosomes against genome instability. Nat Rev Mol Cell Biol 2010, 11:171-181.

20. Osterhage $J$, Friedman KL: Chromosome end maintenance by telomerase. J Biol Chem 2009, 284:16061-16065.

21. Antoniou KM, Margaritopoulos G, Economidou F, Siafakas NM: Pivotal clinical dilemmas in collagen vascular diseases associated with interstitial lung involvement. Eur Respir J 2009, 33:882-962.

22. Kim EJ, Elicker BM, Maldonado F, Webb WR, Ryu JH, Van Uden JH, Lee JS, King TE Jr, Collard HR: Usual interstitial pneumonia in rheumatoid arthritis-associated interstitial lung disease. Eur Respir J 2010, 35:1322-1328.

23. Arnett FC, Edworthy SM, Bloch DA, McShane DJ, Fries JF, Cooper NS, Healey LA, Kaplan SR, Liang MH, Luthra HS, et al: The American Rheumatism Association 1987 revised criteria for the classification of rheumatoid arthritis. Arthritis Rheum 1988, 31:315-324.

24. Kastrinaki MC, Sidiropoulos $P$, Roche $S$, Ringe J, Lehmann S, Kritikos $H$, Vlahava VM, Delorme B, Eliopoulos GD, Jorgensen C, Charbord P, Häupl T, Boumpas DT, Papadaki HA: Functional, molecular and proteomic characterization of bone marrow mesenchymal stem cells in rheumatoid arthritis. Ann Rheum Dis 2008, 67:741-749.

25. In't Anker PS, Noort WA, Scherjon SA, der KC Kleijburg-van, Kruisselbrink AB, van Bezooijen RL, et al: Mesenchymal stem cells in human secondtrimester bone marrow, liver, lung, and spleen exhibit a similar immunophenotype but a heterogeneous multilineage differentiation potential. Haematologica 2003, 88:845-852.

26. Delorme B, Charbord P: Culture and characterisation of human bone marrow mesenchymal stem cells. In Methods in molecular medicine, 2nd edn: tissue engineering. Edited by Hauser $\mathrm{H}$, Fussenegger $\mathrm{M}$. Totowa, New Jersey, USA: Humana Press Inc; 2007.

27. Cawthon RM: Telomere measurement by quantitative PCR. Nucleic Acids Res 2002, 30:e47.

28. Armanios M: Syndromes of telomere shortening. Ann Rev Genomics Hum Genet 2009, 10:45-61.

29. Antoniou KM, Papadaki HA, Soufla G, Siafakas NM: Short telomeres and treatment of pulmonary fibrosis: implications for early intervention. Am J Respir Crit Care Med 2009, 179:970.

30. Cronkhite JT, Xing C, Raghu G, Chin KM, Torres F, Rosenblatt RL, Garcia CK: Telomere shortening in familial and sporadic pulmonary fibrosis. Am J Respir Crit Care Med 2008, 178:729-737.

31. Weiss DJ, Kolls JK, Ortiz LA, Panoskaltsis-Mortari A, Prockop DJ: Stem cells and cell therapies in lung biology and lung diseases. Proc Am Thorac Soc 2008, 5:637-667.

32. Ortiz LA, Gambelli F, McBride C, Gaupp D, Baddoo M, Kaminski N, Phinney DJ: Mesenchymal stem cell engraftment in lung is enhanced in response to bleomycin exposure and ameliorates its fibrotic effects. Proc Natl Acad Sci USA 2003, 100:8407-8411.

33. Germano D, Blyszczuk P, Valaperti A, et al: Prominin-1/CD133+ lung epithelial progenitors protect from bleomycin-induced pulmonary fibrosis. Am J Respir Crit Care Med 2009, 179:939-949.

34. Wang D, Morales JE, Calame DG, Alcorn JL, Wetsel RA: Transplantation of human embryonic stem cell-derived alveolar epithelial type II cells abrogates acute lung injury in mice. Mol Ther 2010, 18:625-634.
35. Armanios MY, Chen JJ, Cogan JD, Alder JK, Ingersoll RG, Markin C, Lawson WE, Xie M, Vulto I, Phillips JA 3rd, Lansdorp PM, Greider CW, Loyd JE: Telomerase mutations in families with idiopathic pulmonary fibrosis. N Engl J Med 2007, 356:1317-1326.

36. Tsakiri KD, Cronkhite JT, Kuan PJ, Xing C, Raghu G, Weissler JC, Rosenblatt RL, Shay JW, Garcia CK: Adult-onset pulmonary fibrosis caused by mutations in telomerase. Proc Natl Acad Sci U S A 2007, 104:7552-7557.

37. Alder JK, Chen JJ, Lancaster L, Danoff S, Su SC, Cogan JD, Vulto I, Xie M, Q X, Tuder RM, Phillips JA 3rd, Lansdorp PM, Loyd JE, Armanios MY: Short telomeres are a risk factor for idiopathic pulmonary fibrosis. Proc Natl Acad Sci USA 2008, 105:13051-13056.

38. Zimmermann S, Voss M, Kaiser S, Kapp U, Waller CF, Martens UM: Lack of telomerase activity in human mesenchymal stem cells. Leukemia 2003, 17:1146-1149

39. Izadpanah R, Trygg C, Patel B, Kriedt C, Dufour J, Gimble JM, et al: Biologic properties of mesenchymal stem cells derived from bone marrow and adipose tissue. J Cell Biochem 2006, 99:1285-1297.

40. Passegue $\mathrm{E}$, Jamieson CH, Ailles LE, Weissman IL: Normal and leukemic hematopoiesis: are leukemias a stem cell disorder or a reacquisition of stem cell characteristics? Proc Natl Acad Sci U S A 100 2003, 1:1184211849.

41. Hemmati HD, Nakano I, Lazareff JA, Masterman-Smith M, Geschwind DH, Bronner-Fraser M, et al: Cancerous stem cells can arise from pediatric brain tumors. Proc Natl Acad Sci U S A 2003, 100:15178-15183.

42. Al Hajj M, Wicha MS, Benito-Hernandez A, Morrison SJ, Clarke MF: Prospective identification of tumorigenic breast cancer cells. Proc Nat Acad Sci U S A 2003, 100:3983-3988.

43. Singh SK, Hawkins C, Clarke ID, Squire JA, Bayani J, Hide T, et al: Identification of human brain tumour initiating cells. Nature 2004, 432:396-401.

44. Reddel RR: Alternative lengthening of telomeres, telomerase, and cancer. Cancer Lett 2003, 194:155-162.

45. Reddel RR, Bryan TM: Alternative lengthening of telomeres: dangerous road less travelled. Lancet 2003, 361:1840-1841.

46. Gonzalo S, Jaco I, Fraga MF, Chen TP, Li E, Esteller M, et al: DNA methyltransferases control telomere length and telomere recombination in mammalian cells. Nat Cell Biol 2006, 8:416-466.

47. Liu L, DiGirolamo CM, Navarro PA, Blasco MA, Keefe DL: Telomerase deficiency impairs differentiation of mesenchymal stem cells. Exp Cell Res 2004, 294:1-8.

48. Simonsen JL, Rosada C, Serakinci N, Justesen J, Stenderup K, Rattan Sl, et al: Telomerase expression extends the proliferative life-span and maintains the osteogenic potential of human bone marrow stromal cells. Nat Biotechnol 2002, 20:592-596.

49. Ferrero I, Mazzini L, Rustichelli D, et al: Bone marrow mesenchymal stem cells from healthy donors and sporadic amyotrophic lateral sclerosis patients. Cell Transplant 2008, 17:255-266.

50. Agostini C: Stem cell therapy for chronic lung diseases: hope and reality. Respir Med 2010, 104:S86-S91.

doi:10.1186/1476-9255-9-27

Cite this article as: Antoniou et al:: Investigation of Telomerase/

Telomeres system in Bone Marrow Mesenchymal Stem Cells

derived from IPF and RA-UIP. Journal of Inflammation 2012 9:27.

\section{Submit your next manuscript to BioMed Central and take full advantage of:}

- Convenient online submission

- Thorough peer review

- No space constraints or color figure charges

- Immediate publication on acceptance

- Inclusion in PubMed, CAS, Scopus and Google Scholar

- Research which is freely available for redistribution 